\title{
Posterior interosseous nerve syndrome due to intramuscular lipoma
}

\author{
M. Allagui • S. Maghrebi • B. Touati • M. Koubaa • \\ R. Hadhri • M. F. Hamdi • A. Abid
}

Received: 28 February 2013 / Accepted: 6 May 2013 /Published online: 21 May 2013

(C) The Author(s) 2013. This article is published with open access at Springerlink.com

\begin{abstract}
Lipomas are extremely common benign soft tissue tumors that are usually subcutaneous and asymptomatic. However, an intramuscular lipoma, occurring adjacent to the proximal radius, may easily cause paralysis of the posterior interosseous nerve because of a specific anatomical relationship of these structures in that area. In this report, we describe an unusual case of a 48-year-old-woman with a posterior interosseous nerve syndrome due to an intramuscular lipoma. The patient had good recovery after surgery and rehabilitation physiotherapy.
\end{abstract}

Keywords Intramuscular lipoma $\cdot$ Posterior interosseous nerve $\cdot$ Compression

\section{Introduction}

Lipomas are the most common benign soft tissue tumors and occur in the subcutaneous tissue. Rarely, lipomas present in the deep soft tissue such as intermuscular, intramuscular, and parosteal sites. It tends to be indolent, and symptoms caused by nerve compression are unusual. However, an intramuscular lipoma occurring in the proximal forearm causes paralysis of the posterior interosseous nerve (PIN) because of its anatomical relationship in that area. Below the elbow, the PIN passes beneath the extensor carpi radialis brevis muscle and then continues between the

M. Allagui $(\bowtie) \cdot$ S. Maghrebi $\cdot$ B. Touati $\cdot$ M. Koubaa $\cdot$

M. F. Hamdi • A. Abid

Department of Orthopaedic and Traumatology, Fattouma

Bourguiba Hospital, Monastir, Tunisia

e-mail: medallagui@yahoo.fr

R. Hadhri

Department of Anatomopathology, Fattouma Bourguiba Hospital, Monastir, Tunisia superficial and deep layers of the supinator muscle. The proximal edge of the supinator muscle forms an arch, the arcade of Frohse [1]. The PIN is vulnerable in this region [2]. We report a new case of an intramuscular lipoma with compression of the PIN.

\section{Case report}

A 48-year-old woman presented with spontaneous inability to extend the fingers of the left hand. She noticed a gradually increasing inability to extend the fingers over 6 months. She was unable to perform her domestic activities because of weakness and paresis of the hand; she denied any trauma or other diseases. Examination revealed a swelling of $5 \times 3 \mathrm{~cm}$ in the anterolateral aspect of the left forearm in the region of the brachioradialis muscle just below the elbow. The swelling was firm in consistency, immobile, not fixed to the skin; there were no dilated veins over the swelling or signs of inflammation. The elbow function was normal, as was the flexor strength of the wrist and fingers; however, there was a decrease in the extension strength of the wrist and metacarpophalangeal joints of the fingers and thumb (power 3/5). There was no sensory deficit. Magnetic resonance imaging of the elbow objectified an intramuscular mass, of 8 -cm-long axis depending on the supinator muscle, pathognomonic of a lipoma (Figs. 1 and 2). Surgical excision was recommended. General anesthesia was administered, and an incision was made over the mass. The incision of the supinator muscle exposed a fatty encapsulated mass (Fig. 3). The dissection of the mass revealed that it is constricting the PIN (Figs. 4 and 5). The nerves were carefully released, and a lipoma was removed. The PIN was preserved, without damage (Fig. 6). 


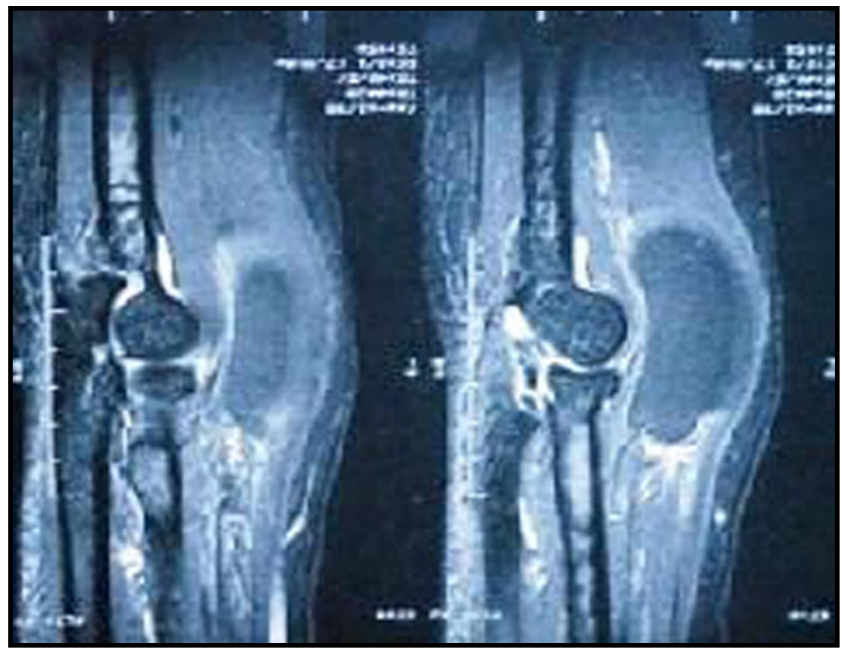

Fig. 1 T2 FAT SAT MRI images, showing an intramuscular mass on the supinator muscle

Fig. 2 T1 MRI images, showing an intramuscular mass on the supinator muscle
Histological examination of the tumor confirmed it to be a benign lipoma (Figs. 7 and 8). In the early postoperative period, the radial nerve recovered its function. A physiotherapy program was started 2 weeks after surgery. The patient recovered well, and 6 weeks after surgery, she resumed her activities. No local recurrence was detected at 18 months after surgery.

\section{Discussion}

Symptomatic radial nerve compression is relatively uncommon, and when it is caused by a lipoma, it commonly occurs at the elbow level, compromising the posterior interosseous branch [3, 4]. Lipomas are benign tumors composed of mature adipocytes, and they represent one of the most prevalent tumors of mesen-
Fig. 3 The incision of the supinator muscle exposed a fatty mass
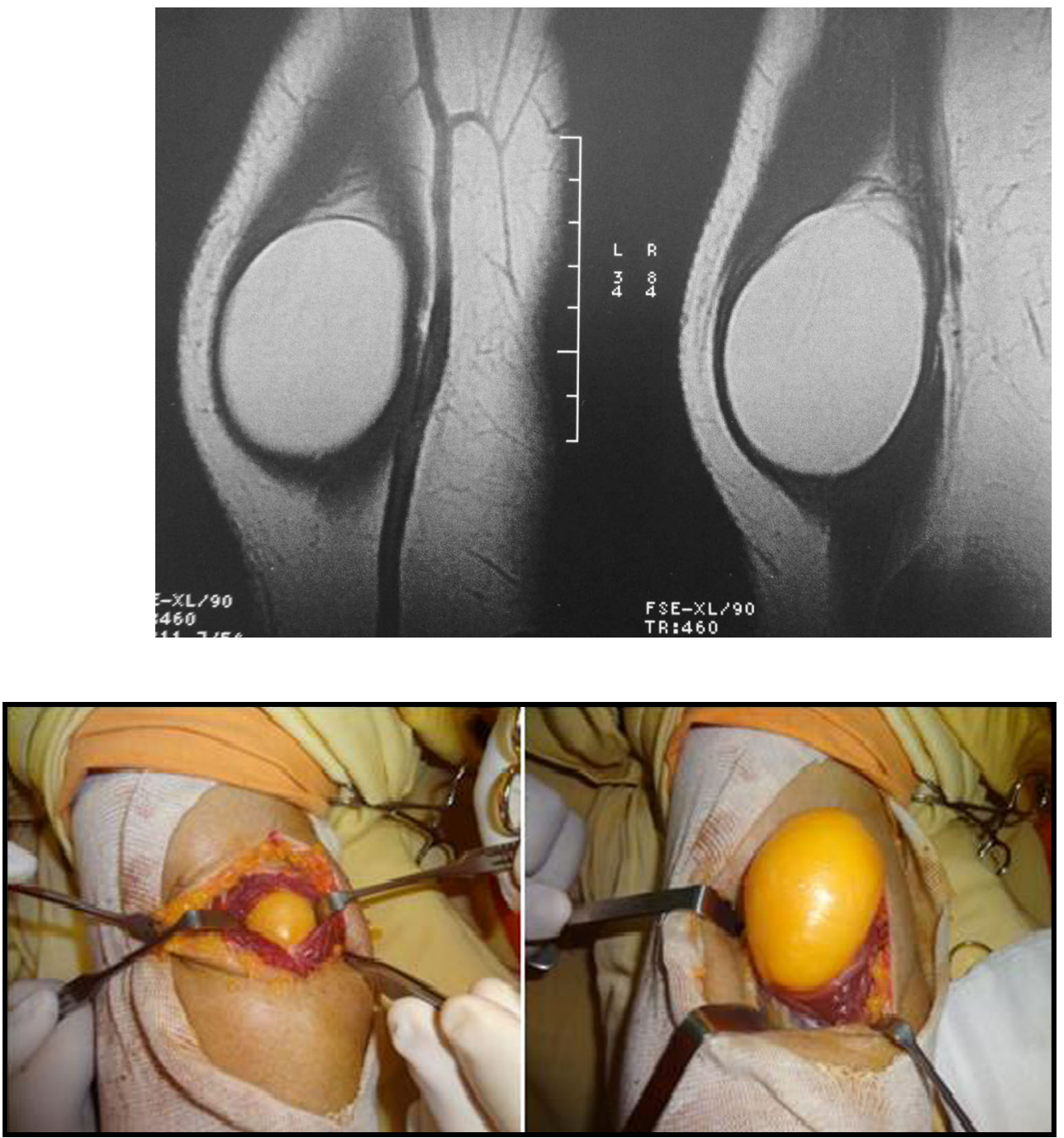


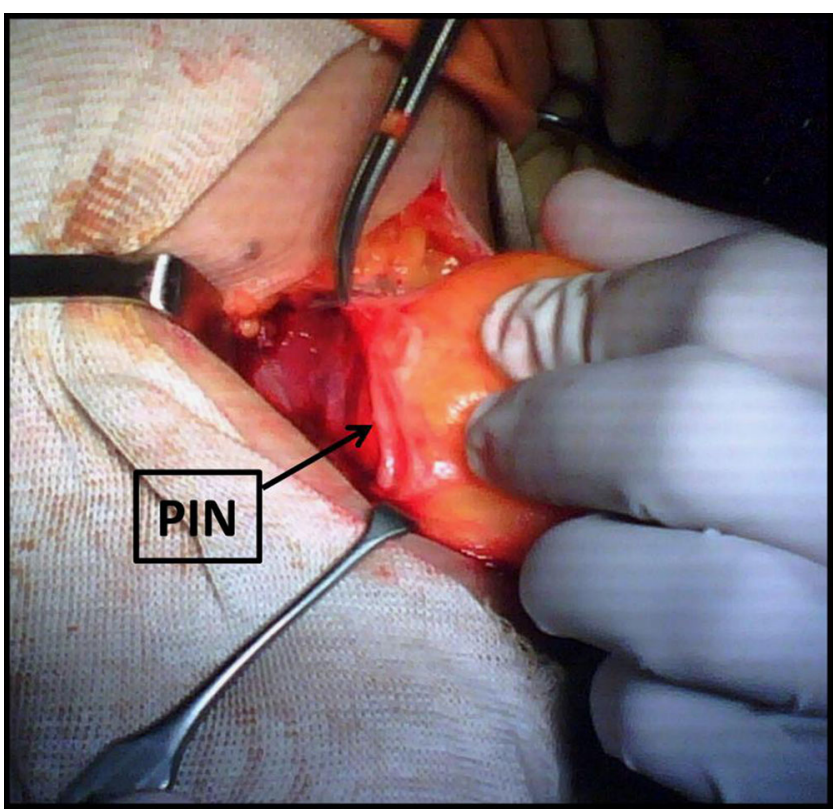

Fig. 4 The dissection of the mass revealed that it is constricting the PIN

chymal origin [4-6]. Lipomas and other tumors over the radial nerve are rare causes of chronic entrapment of the PIN, but they can produce a classic picture of PIN syndrome (PINS). There are some reports of compression neuropathies [7-10] of the upper limb caused by this kind of tumor. Other causes of PIN compression have been described: rheumatoid synovial cysts [11], ganglion [12-14], myxoma [15], pseudogout [16], and chondroma [17], among others. Intramuscular lipoma

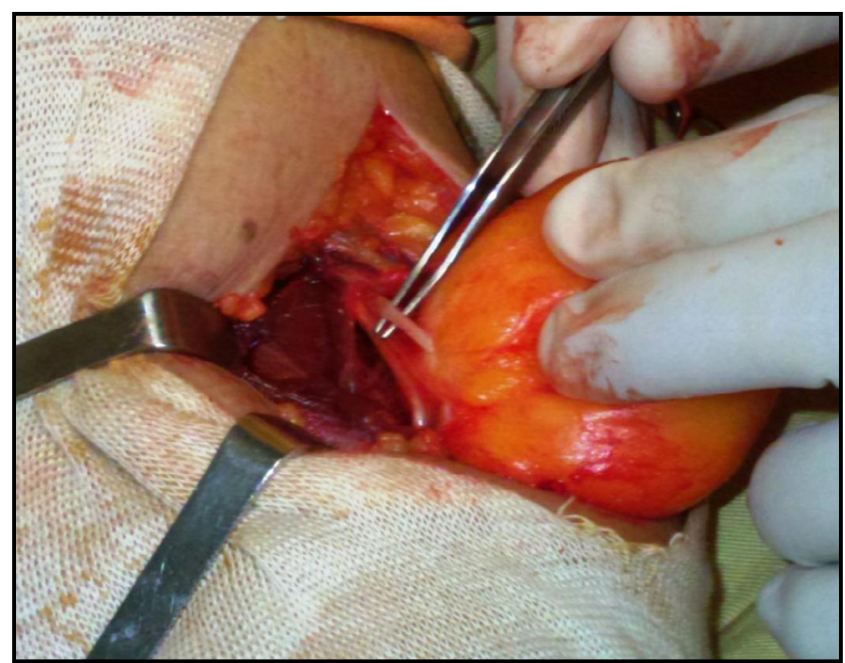

Fig. 5 Liberation of the PIN

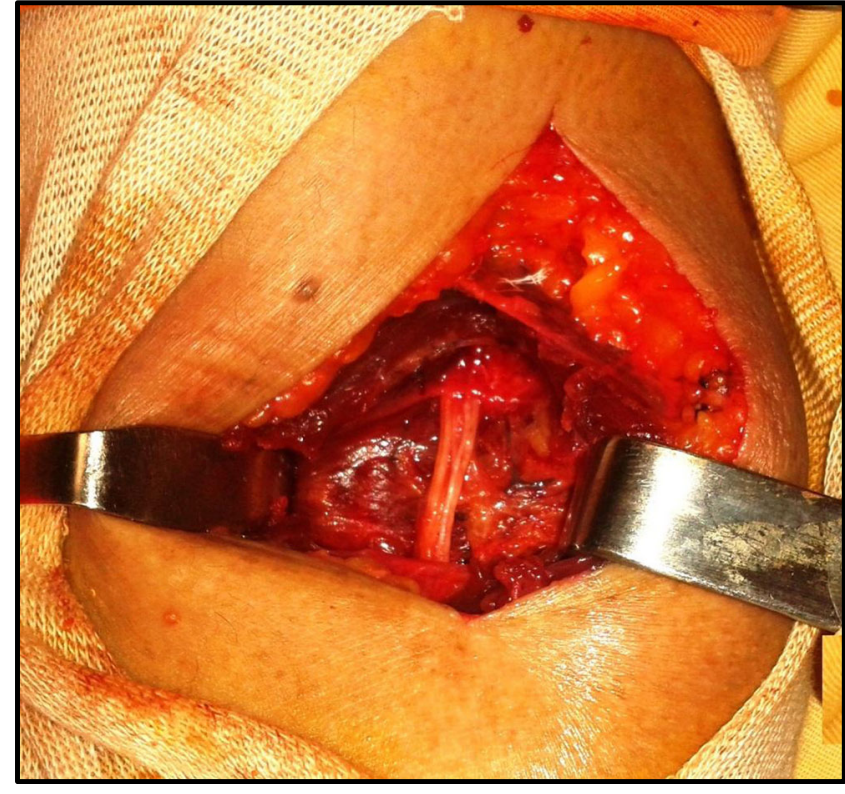

Fig. 6 After excision of the mass, the superficial radial nerve and the PIN were preserved

shows an infiltrative nature to the surrounding striated muscle, and the lesion is usually not encapsulated [18], although the pathogenesis of an intramuscular lipoma remains obscure [18].

The diagnosis of PINS is based on clinical history and physical examination and is confirmed by electrophysiological

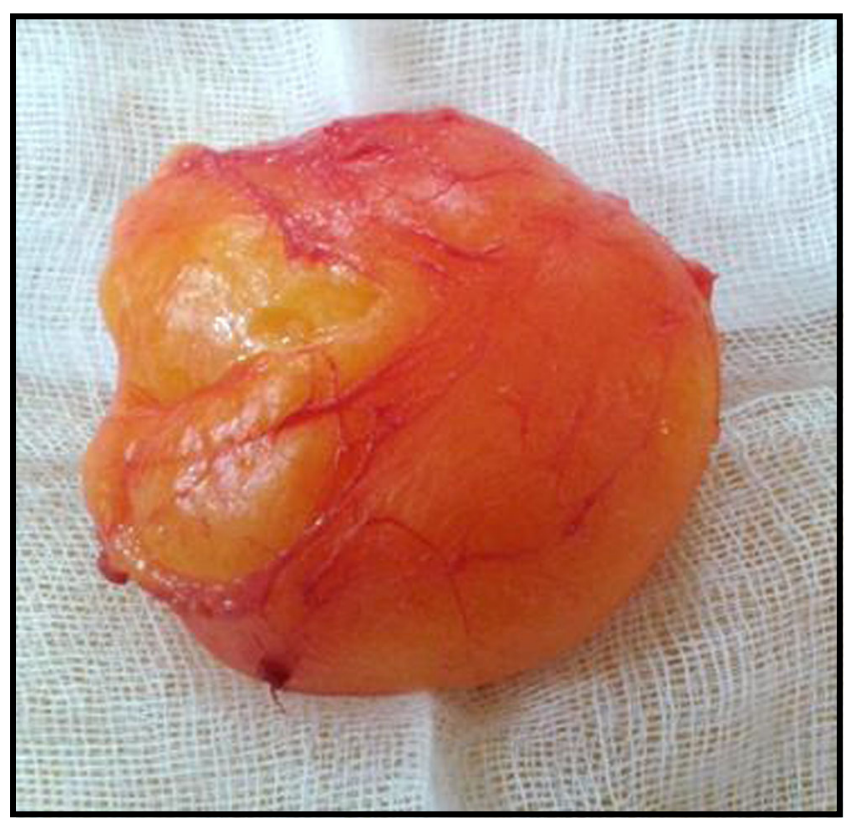

Fig. 7 The fatty mass 
Fig. 8 a Lobules of mature fat cells (hematoxylin and eosin, $\times 40$ ). b Mature fat cells entrapping skeletal muscle fibers (hematoxylin and eosin, $\times 100$ )
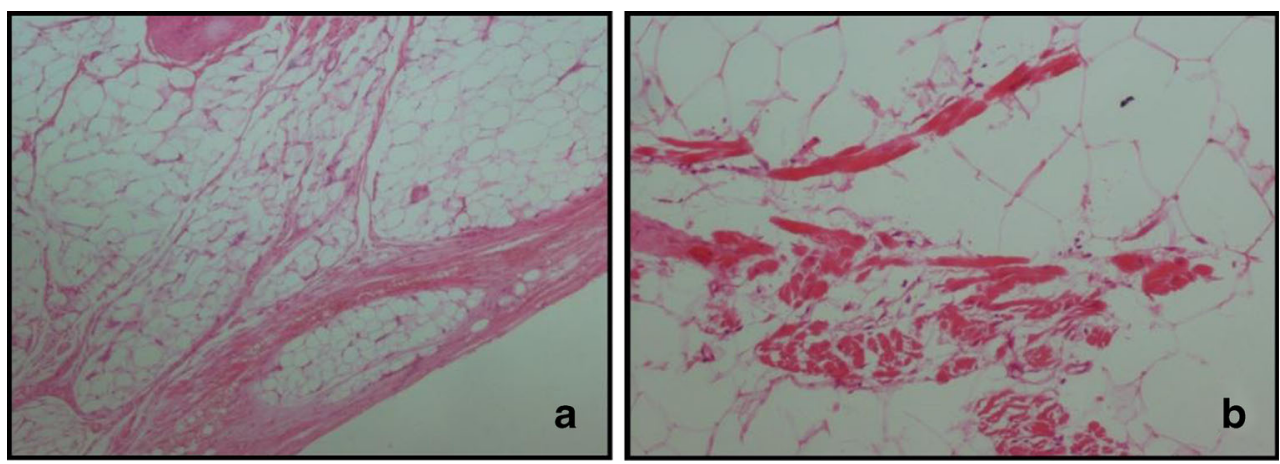

studies. Classically, this syndrome has neither pain nor other sensory symptoms, but there are cases of forearm pain and paralysis of the extensor muscles of the forearm. If there is any suspicion, based on clinical examination, of a mass as the causative factor of PINS, MRI scan is the imaging method of choice for evaluating their presence and extent. In this clinical case, however, the lipoma was located intramuscularly, and there was a palpable mass on the forearm.

Surgical excision of an intramuscular lipoma is recommended to prevent involvement of the PIN or to ensure optimal recovery when the nerve is already compressed by the tumor [19]. The recovery of the neurological deficit relates to the duration of symptoms, the longest reported duration of symptoms with full recovery postoperatively being 18 months [20]. The prognosis after excision of a lipoma is excellent, with only one recurrence described in the literature. Malignant transformation has not been reported.

Jürgens and Hampt, in a study of 20 patients with PIN paralysis, concluded that the result of the operation depended on the duration of the symptoms, so that long-lasting paralysis made reinnervation less likely to occur [21]. According to the study by De-song et al., early diagnosis and surgery are very important in the treatment of PINS [22]. Prompt diagnosis and early removal of the compressing mass facilitate quick neurological recovery.

\section{Conclusion}

The prognosis of PINS depends on an early diagnosis, followed by an immediate surgical excision based on MRI findings. The paralysis of the PIN is clinically evident; electrophysiological exploration would confirm the diagnosis and the site of entrapment. After surgical excision of the mass, rehabilitation is needed for rapid functional recovery of the upper extremity.

\section{Conflict of interest None}

Open AccessThis article is distributed under the terms of the Creative Commons Attribution License which permits any use, distribution, and reproduction in any medium, provided the original author(s) and the source are credited.

\section{References}

1. Werner CO (1987) Paralysis of the posterior interosseous nerve caused by tumour: brief report. J Bone Joint Surg Br 69:670 671

2. Capener N (1966) The vulnerability of the posterior interosseous nerve of the forearm. J Bone Joint Surg Br 48:770-773

3. Carlson N, Logigian EL (1999) Radial neuropathy. Neurol Clin $17: 499-523$

4. RD Leffert (1972) Lipomas of the upper extremity. J. Bone Joint Surg. Am, 54:1262-6

5. Harrington AC, Adnot J, Chesser RS (1990) Infiltrating lipomas of the upper extremities.J. Dermatol. Surg Oncol 16:834-7

6. Scherl MP, Biller HF, Shah K, Som PM (1986) Recurrent infiltrating lipoma of the head and neck: case report and literature review. Arch Otolaryngol Head Neck Surg 112:1210-2

7. Fitzgerald A, Anderson W, Hooper G (2002) Posterior interosseous nerve plasy due to parosteal lipoma. Journal of Hand Surgery 27B(6):535-537

8. Ganapathy K, Winston T, Seshadri V (2006) Posterior interosseous nerve plasy due to intermuscular lipoma. Surg Neurol 65:495496

9. Henrique A (2002) A high radial neuropathy by parosteal lipoma compression. J Shoulder Elbow Surg 11:386-388

10. Pidgeon KJ, Abadee P, Kanakamedala R, Uchizono M (1985) Posterior interosseous nerve syndrome caused by an intermuscular lipoma. Arch Phys Med Rehabil 66:468-471

11. Ishikawa H, Hirohata K (1990) Posterior interosseous nerve syndrome associated with rheumatoid synovial cysts of the elbow joint. Clin Orthop Relat Res 254:134-139

12. Bowen TL, Stone KH (1966) Posterior interosseous nerve paralysis caused by a ganglion at the elbow. J Bone Joint Surg $\mathrm{Br}$ 48:774-776 
13. Hashizume H, Nishida K, Nanba Y, Shigeyama Y (1996) Nontraumatic paralysis of the posterior interosseous nerve. J Bone Joint Surg Br 78:771-776

14. Ogino T, Minami A, Kato H (1991) Diagnosis of radial nerve palsy caused by ganglion with use of different imaging techniques. J Hand Surg Am 16:230-235

15. Valer A, Carrera L, Ramirez G (1993) Myxoma causing paralysis of the posterior interosseous nerve. Acta Orthop Belg 59:423-425

16. Taniguchi Y, Yoshida M, Tamaki T (1999) Posterior interosseous nerve syndrome due to pseudogout. J Hand Surg Br 24:125-127

17. De Smet L (2005) Posterior interosseous neuropathy due to compression by a soft tissue chondroma of the elbow. Acta neurol Belg 105:86-88
18. Bjerregaard P, Hagen K, Daugard S, Kofoed H (1989) Intramuscular lipoma of the lower limb: long term follow-up after local resection. J Bone Joint Surg Br 71:812-815

19. Lidor C, Lotem M, Hallel T (1992) Parosteal lipoma of the proximal radius: a report of five cases. J Hand Surg Am 17:1095-1097

20. Berry JB, Richard MH (1973) Parosteal lipoma producing paralysis of the deep radial nerve. South Med J 66:1298-1300

21. Jürgens R, Haupt WF (1987) The supinator syndrome: study of the course in 20 patients and therapeutic recommendations. Nervenarzt 58:30-32

22. Chen DS, Gu YD, Zhang GM, Yan JG, Chen XM (1994) Entrapment of posterior interosseous nerve of forearms: report of 25 cases. Chin Med J (Engl) 107:196-99 